\title{
Assessment of Susceptibility towards iAs Induced Carcinogenesis in West Bengal, India
}

\author{
Archismaan Ghosh, Apurba Mukherjee, Sutapa Mukherjee and Madhumita Roy*
}

Department Environmental Carcinogenesis \& Toxicology, Chittaranjan National Cancer Institute, 37, S P Mukherjee Road, Kolkata, India

*Corresponding author

\section{Keywords}

Arsenic, ROS, carcinogenesis, cytokines, telomerase, DNA repair, $\mathrm{NF}-\mathrm{\kappa B}$

Article Info

Accepted:

15 February 2020 Available Online: 10 March 2020

\section{A B S T R A C T}

Inorganic Arsenic (iAs) contamination of groundwater had been a major health hazard. In West-Bengal, many areas had been found to have high level of iAs in groundwater. Chronic exposure to iAs may lead to the generation of Reactive Oxygen Species (ROS) and Reactive Nitrogen Species (RNS). This results in DNA damage, inflammation, impairment of repair activity, thereby culminating in carcinogenesis. Higher telomerase activity may be another manifestation of iAs exposure. This is a pilot study involving 15 subjects residing in an arsenic endemic area of West-Bengal. Accumulation of iAs was tested in the nail, hair and blood samples of these individuals. Extent of ROS, RNS, DNA damage, expression of repair enzymes and status of pro-inflammatory cytokines had been studied. Telomerase activity and NF- $\mathrm{KB}$ were also studied. 15 samples were collected from subjects residing in an area having iAs within safe limits. It was observed that in samples from iAs endemic region, ROS and RNS generation was high, followed by DNA damage. These individuals showed higher telomerase activity compared to the control. Status of NF- $\kappa \mathrm{B}$ and pro-inflammatory cytokines had been found to be elevated in comparison to the control. Therefore, these parameters could assess the susceptibility of these individuals towards carcinogenesis.

\section{Introduction}

The metalloid arsenic is commonly found in the earth's crust, ranking $20^{\text {th }}$ in the abundance amongst other elements and existing in both +5 and +3 oxidation states. It exists both in organic and inorganic state (Roy et al., 2014). Inorganic arsenic (iAs) is more harmful in the biological system, than their organic counterpart. They are released from the rocks into groundwater naturally as well as anthropogenically (Martinez et al., 2011), contaminating the groundwater water.

Groundwater arsenic contamination is a major health hazard worldwide. Chronic exposure to 
iAs through consumption of contaminated groundwater leads to arsenicosis, gastrointestinal and liver ailments, respiratory and cardiovascular disorders, hematological problems among others. Cancer of skin, liver, kidney bladder etc. are the most serious outcomes of chronic exposure to this metalloid (GuhaMazumder et al., 2011). A correlation between iAs exposure and generation of reactive oxygen species (ROS) and Reactive Nitrogen Species (RNS) have been observed. These active species include peroxyl radicals, superoxide radicle, singlet oxygen, hydroxyl radical etc. produced via the Fenton reaction within the mitochondria as well as in the cell membrane via the NADPH oxidase (Smith et al., 2011; Jomova et al., 2011).

Cell transformation induced by arsenic is mediated by increased cellular levels of ROS, which causes damage to the cellular components including nucleic acid, thereby inducing DNA base lesions and strand breaks (Cadet and Wagner, 2013; Sarkar et al., 2014). Oxidative base lesions in chromosomal DNA are normally recognized and repaired by base excision repair enzymes including 8Oxoguanine glycosylase (OGG1) (Roy et al., 2011). Impairment of repair machinery due to inhibition of a number of enzymes involved in repair of damage has been observed. This damage is caused due to iAs induced generation of ROS, which leads to sustenance of the damage.

Important DNA repair processes like Base Excision Repair (BER), Nucleotide Excision Repair (NER) and Homologous Recombination Repair (HRR) are affected by iAs (Ebert et al., 2011; Roy et al., 2015), disrupting the repair system. Chronic exposure to iAs also leads to alteration of immune response. Prolonged inflammatory condition has been observed in chronic iAs exposed populations which ultimately lead to cancer (Dangleben et al., 2013). Telomeres are a region of repetitive nucleotide sequences at each end of a chromosome which maintain genomic integrity in normal cells. Their progressive shortening during successive cell divisions induces chromosomal instability, thus halting further cell division. The length of the telomere is maintained by an enzyme telomerase, which adds guanine-rich repetitive sequence to the telomere, thus maintaining its length as well as controlling the cell cycle. Reports reveal that ROS can induce activation of telomerase in cancer cells through the activation of protein kinase B (AKT) (Jafri et al., 2016 ).

Therefore, iAs which is a potent inducer of ROS can also influence activity of telomerase (Ferrario et al., 2009). Telomere length and telomerase activity are crucial for cancer initiation and the survival of tumors. Genes that are responsible for the control of length of telomere have been mapped (Khairul et al., 2017). Genetic and geographical variations may play a crucial role in arsenic induced carcinogenicity.

Therefore, identification of susceptible population based on certain protein and genetic factors will help to understand the predominance of individual variation on development of carcinogenesis. Understanding the mechanism, such as DNA repair capacity, telomerase activity and expression, impaired immune status and prolonged inflammation may provide individual based data identifying high-risk groups.

Affected areas have been identified in West Bengal, where level of arsenic is much higher than the WHO recommended limit of $10 \mu \mathrm{g} / \mathrm{L}$ (Multhoff et al., 2012) and a pilot study was conducted. Based on certain parameters, it may be possible to identify an individual who is susceptible to develop carcinoma. 


\section{Materials and Methods}

\section{Identification and estimation of arsenic contaminated areas and recruitment of volunteers}

Several areas of South 24-Parganas have been reported to contain higher level of arsenic in ground water. Samples of water had been collected and tested for their arsenic content. 15 volunteers have been selected from an area where high level of iAs has been found in ground water. Blood, nail and hair samples were collected from volunteers taking consent and filling up the informed consent form. Permission from Institutional Ethics Committee was taken (vide IEC. Ref: A4.311/08/2016). These volunteers belong to the same socio-economic status. Nail, hair and $10 \mathrm{ml}$ blood was taken from each individual. Another area in the adjoining area, where level of iAs in ground water was within the safe limit was identified and 15 volunteers were recruited, which was the control group.

The amount of arsenic was quantified using injection hydride generation atomic absorption spectroscopy (HG-AAS). Based on this data the affected and non-affected regions were identified and volunteers from both these regions were included in this study. Arsenic level was also measured in the blood, hair and nails of the volunteers. To quantify arsenic in the blood, hair and nails, samples were digested in nitric acid and hydrogen peroxide in a microwave digestion system MARS 6 and then were subjected to Atomic Absorption Spectroscopy.

\section{Isolation of leukocytes and extraction of proteins}

Leukocytes were isolated from heparinized blood according to the lab protocol of (Roy et al., 2011). Heparinized blood was mixed with Solution A $(10 \mathrm{mmol} / \mathrm{l}$ of Tris- $\mathrm{HCl}$ and
$0.87 \%$ of $\mathrm{NH}_{4} \mathrm{Cl} ; \mathrm{pH} 7.2$ ) in the ratio $1: 3$ and was kept at $4^{\circ} \mathrm{C}$ for $30 \mathrm{~min}$. It was centrifuged at $1200-1400 \mathrm{rpm}$ for $30 \mathrm{~min}$. The pellet was suspended in solution A and centrifuged for $10 \mathrm{~min}$. To the resultant pellet, $500 \mu \mathrm{l}$ of solution B $(0.25 \mathrm{~mol} / \mathrm{l}$ mesoinositol, $10 \mathrm{mmol} / \mathrm{l}$ $\mathrm{NaH}_{2} \mathrm{PO}_{4}$ and $1 \mathrm{mmol} / \mathrm{l} \mathrm{MgCl}_{2} ; \mathrm{pH}$ 7.2) was added and centrifuged at $1200-1400 \mathrm{rpm}$ for $10 \mathrm{~min} .500 \mu \mathrm{l}$ of wash buffer $(200 \mathrm{mmol} / \mathrm{l}$ of HEPES.KOH, $600 \mathrm{mmol} / \mathrm{l}$ of $\mathrm{MgCl}_{2}, 500$ $\mathrm{mmol} / \mathrm{l}$ of KCl, $25 \mathrm{mmol} / \mathrm{l}$ of DTT) was added to the pellet and centrifuged at $3000 \mathrm{rpm}$ at $4^{\circ} \mathrm{C}$ for $4 \mathrm{~min}$. The supernatant was poured off and $200 \mathrm{ml}$ of the lysis buffer $(1 \mathrm{~mol} / \mathrm{l}$ of Tris- $\mathrm{HCl} \mathrm{pH} \mathrm{7.5,} 600 \mathrm{mmol} / \mathrm{l}$ of $\mathrm{MgCl}_{2}, 100$ $\mathrm{mmol} / \mathrm{l}$ of EGTA, $100 \% \beta$ mercaptoethanol, $10 \%$ CHAPS, $100 \%$ glycerol) was added. The mixture was then kept on ice for $30 \mathrm{~min}$. The lysate was centrifuged at $1200 \mathrm{rpm}$ at $4^{\circ} \mathrm{C}$ for $20 \mathrm{~min}$. Experiments have been conducted with the final supernatant.

\section{Estimation of ROS generation}

The excess generation of ROS was estimated by Varian Cary Eclipse Fluorescence Spectrophotometer. Leukocytes were suspended in HBS (Hepes buffered Saline $\mathrm{pH}$ - 7.4). ROS generation was measured according to (Balasubramanyam et al., 2003) and 2', 7'-dichloro-fluorescindiacetate (DCFDA) was added to the cell suspension at a final concentration of $10 \mu \mathrm{M}$ per litre. Then the samples were incubated in the dark for 45 minutes and fluorescence was measured at $530 \mathrm{~nm}$. The presence of ROS was determined by the fluorescence intensity produced in the cells due to the generation of dichlorofluorescein.

\section{Estimation of RNS generation}

Estimation of nitrogen species was carried out with the isolated leukocytes. The generation of NO by the RNS was measured with modified Griess reagent (Green et al., 1982). 
The density of cells in each sample were counted and equalized. $1 \mathrm{ml}$ of the cell suspension was incubated with equal volume of Griess reagent ( $1 \%$ sulphanilamide, $0.1 \%$ naphthylethylenediamine-dihydrochloride and $5 \%$ orthophosphoric acid) at $26^{\circ} \mathrm{C}$ for $30 \mathrm{~min}$ in a humid chamber.

The absorbance was recorded in a spectrophotometer at $550 \mathrm{~nm}$ against a standard blank. The generation of RNS was determined using a standard curve of sodium nitroprusside.

\section{Estimation of DNA damage by Single cell gel electrophoresis}

Leukocytes isolated from the blood of the volunteers were used to study DNA damage via Single Cell Gel electrophoresis or Comet assay. $0.6 \%$ Low melting agarose (LMA) containing $20 \mu \mathrm{l}$ of leukocytes was layered on frosted slides pre-coated with $0.75 \%$ Normal melting agarose (NMA) and was allowed to solidify.

These agarose coated cells were lysed by immersing these slides in lysis buffer $(2.5 \mathrm{M}$ $\mathrm{NaCl}, 0.1 \mathrm{M} \mathrm{Na}_{2}$ EDTA, 10nM TRIS, $0.3 \mathrm{M}$ $\mathrm{NaOH} \& 1 \%$ TritonX; pH-10) overnight at $4 \mathrm{C}$. Electrophoresis was performed the following day in highly alkaline buffer (10 $\mathrm{mM} \mathrm{NaOH}, 0.2 \mathrm{~m} \mathrm{Na} 2$ EDTA; $\mathrm{pH}>13$ ) for 25 minutes at $15 \mathrm{~V}, 220 \mathrm{~mA}$. Slides were stained with $\mathrm{EtBr}$ and observed under fluorescent microscope.

\section{Western Blot analysis}

Cell lysates were prepared from the leukocytes which were isolated from the blood of the volunteers. The protein concentration was estimated by the Lowry's method and $50 \mu \mathrm{g}$ of protein was loaded in each well. Electrophoresis was performed in SDS-polyacrylamide gel.
Proteins were separated based on their molecular weight and blotted onto a nitrocellulose membrane using a transfer buffer (250 mM TRIS, $192 \mathrm{mM}$ glycine, 10\% Methanol). After blocking with Bovine Serum Albumin (BSA), membranes were washed with TRIS Buffered Saline pH 7.5 (25 mM TRIS $\mathrm{HCl}$ and $150 \mathrm{mM} \mathrm{NaCl}$ ) 4-5 times and then incubated with primary antibodies overnight at $4 \mathrm{C}$ with constant shaking.

The blots were washed 4 times with TBST followed by treatment with either alkaline phosphatase conjugate anti-mouse or antirabbit $\operatorname{IgG}$ (1:2000 dilutions in TBS) as per need at $4 \mathrm{C}$. Membrane was then washed 4 times and incubated with substrate (BCIP/NBT) to visualize the proteins bands.

\section{Telomerase assay}

Telomerase assay was performed by TRAPEZE Gel-Based Telomerase Detection Kit manufactured by Merck-Millipore. This kit analyses the telomerase activity using TRAP assay described by (Kim et al., 1994). This assay utilizes a two enzyme system, the first step being addition of telomeric repeats by the telomerase itself present in the samples onto the 3' end of an oligonucleotide substrate.

The second step being the PCR amplification of these telomeric repeats using forward and reverse primers. The products of the PCR are to be electrophoresed onto a polyacrylamide gel after staining with a fluorescence dye and the ladder obtained has to be observed using a gel documentation system or a UV Transilluminator.

Intensities of clearly separated bands (amplified product of telomeric repeat) have been determined using the software Image Master. The intensity of the bands obtained from affected samples were divided by the 
intensity obtained from control samples (average of 15 control) to get the fold change.

\section{Results and Discussion}

\section{Arsenic estimation in the water and tissue sample}

The arsenic content in the water and in the tissues of the volunteers was estimated by the HG-AAS and have been represented as a bar graph in Fig.1. The water consumed by the volunteers were estimated for the iAs content and the results are shown in Fig 1A. For blood, hair and nail, the values are average of 15 samples as shown in Fig 1B. The data shows elevated arsenic content in blood, hair and nails, which correlated with the high iAs content in the water they are exposed to. The data clearly indicates that individuals residing in the affected region had greater accumulation of arsenic in the blood, hair and nails in comparison to the volunteers from the control region.

\section{Estimation of ROS, RNS and DNA damage}

Exposure to inorganic arsenic leads to generation of reactive oxygen species (ROS) and reactive nitrogen species (RNS), ultimately culminating to DNA damage. The DNA damage, if not repaired, leads to mutation and finally initiation of carcinogenesis.

Hence, it is worthwhile to measure the ROS and RNS level in the blood samples (leukocytes) of individuals in control, as well as exposed to high level to inorganic arsenic in ground water. Extent of DNA damage has been studied by Single Cell Gel Electrophoresis (SCGE or comet assay), which is a consequence of excess generation of ROS and RNS. Fig 2A shows a representative photograph of comet tail in control and iAs exposed population. ROS,
RNS, comet tail length (TL) and Olive Tail Moment (OTM) have been shown in Fig 2B. Values are average of 15 samples and they are represented as fold increase (i.e. the normalized value in respect to the mean of control individuals).

Expression of DNA repair enzymes, proinflammatory cytokines (Il-2 and IL-6) as well as transcription factor $\mathrm{NF}-\kappa \mathrm{B}$

DNA damage can be repaired by several DNA repair mechanisms within the cell but inorganic arsenic is known to hinder the DNA repair mechanisms by inhibiting the activity and expression of DNA repair enzymes. Impairment of DNA repair pathways lead to accumulation of arsenic induced damage thus promoting carcniogenesis. In this pilot study we looked into the expression of DNA repair enzymes in the leukocytes isolated from the blood samples of the volunteers. The expression of few DNA repair enzymes belonging to Base Excision Repair (BER) pathway and Nucleotide Excision Repair (NER) pathway were investigated.

Fig 3A depicts representative western blot bands in control, as well as iAs exposed groups. Expression of OGG1 (DNA Glycosylase) was increased, while other repair enzymes like XRCC1, DNA ligase I, DNA ligase III and PARP 1 decreased significantly in the leukocytes of the volunteers from the exposed region in comparison to the leukocytes of the control volunteers. For DNA Polymerase $\beta$, no such alteration has been noted.

$\mathrm{NF \kappa B}$ is a transcription factor responsible for the transcription of pro-inflammatory cytokines. Fig 3C shows the representative western blot bands of IL-2, IL-6 and two main sub units of NFאB, namely p50 and p65. Exposure to iAs promotes inflammation, which in turn facilitates carcinogenesis and 
maintain tumor microenvironment. Band intensities, which are average of 15 samples have been represented in bar diagrams. Fig 3B shows the average band intensities of repair enzymes, whereas Fig 3D shows the mean band intensities of IL-2, IL-6 and NF$\kappa \mathrm{B}$ subunits $\mathrm{p} 50$ and $\mathrm{p} 65$.

\section{Telomerase activity as a biomarker of cancer risk}

The chromosome ends are protected by telomeres and protein complexes which prevent them from erosion. These telomeres are tandem repeat sequences of (TTAGGG) which are added to the chromosome by telomerase, a ribonucleoprotein terminal transferase. Cancer cells generally have high Telomerase activity which indicates the excess replicative potential of the cancer cells.

Therefore, telomerase activity can be a potent biomarker of cancer risk (Haycock et al., 2017). The telomerase activity was studied in the 15 volunteers from arsenic endemic, as well as control areas. Fig 4 shows the representative telomerase pattern. Lanes 1 and 2 represent control samples. Lanes 3-17 denote telomerase activity of 15 affected individuals residing in the arsenic endemic areas. In the control group only $36 \mathrm{bp}$ internal control band was observed, showing less telomerase activity.

Whereas, samples from arsenic affected areas showed a typical ladder formation with 6 base increments starting at 50 nucleotides along with the 36 bp internal control band. A similar laddering pattern was observed in the positive control. Interesting finding is that there is an inter-individual variation in the extent of telomerase activity.

A significant increase in the telomerase activity has been obtained in the samples from arsenic endemic regions, except for one sample (Lane 9). Telomerase activity in 15 individuals exposed to iAs have been tabulated in Table 1, as obtained from the band intensities measured using the software Image Master.

This study clearly indicates a higher telomerase activity in the samples obtained from arsenic endemic areas. These individuals may be at higher risk of developing cancer. Activated telomerase may indicate higher risk of susceptibility to carcinogenesis in the volunteers from arsenic affected areas.

\section{Correlation between parameters}

Generation of ROS/RNS appears to be responsible for modification of several parameters. A good linear correlation has been obtained between the different parameters studied. High degree of correlation (Table 2) between generation of ROS and change in the status of other parameters reflects the fact that arsenic induced generation of ROS may lead to a plethora of events, culminating in carcinogenesis. Results show that the parameters aberrantly expressed in iAs endemic region may be due to excessive generation of ROS, as evident from the correlation coefficients, except that for DNA polymerase $\beta$ (not shown).

There had been no change in the expression of this enzyme. For OGG1, expression was low in control, which increased with exposure to iAs. The positive value signifies that OGG1 expression is induced by ROS, unlike other repair enzymes. For all other repair enzymes, higher expression in control gets down regulated by generation of ROS (indicated by negative correlation coefficient). For pro-inflammatory cytokines, level increased with increase in ROS; similarly, for transcription factor NFkB p50 and p65 subunits, expression was upregulated by 
increase in ROS. The correlation coefficient values reflect the same.

Arsenic has been defined as a Class I human carcinogen by International Agency on Cancer Research (IARC) (Martinez et al., 2011). In India, particularly in West Bengal, groundwater arsenic contamination is alarming. Scientific literature and many other studies for over two decades have reported the link between arsenic exposure and increase in cancer incidences (Karagas et al., 2004; Smith et al., 2009). This pilot study aims to identify a susceptible population based on certain paramaters mentioned before. These parameters have been found to be expressed more than those in the control. These individuals from arsenic endemic area may be at higher risk of cancer, due to chronic exposure to high level of iAs. Arsenic content in the blood, hair and nails of the volunteers were estimated and it was found that, the 15 volunteers who hail from the high arsenic endemic region had much higher accumulation of arsenic in their hair and nails as well as in the blood. This is a clear indication of arsenic exposure. Besides, the hair, nail and blood samples of the volunteers residing in low arsenic contaminated regions had almost negligible accumulation of arsenic within them.

Arsenic is not a direct acting mutagen (Schoen et al., 2004) but is known to act via the generation of ROS (Zhang et al., 2015). Excess generation of ROS leads to DNA damage. The results above show that ROS and DNA damage is quite high in the population chronically exposed to high level of arsenic in ground water. The greater Tail Lengths and greater Olive Tail Moments in the single cell gel electrophoresis assay indicates higher extent of DNA damage (Kumaravel et al., 2009). Arsenic is known to inhibit the activity of DNA repair enzymes which leads to accumulation of damaged
DNA, ultimately promoting carcinogenesis (Andrew et al., 2003). In this pilot study, we investigated the expression of DNA repair enzymes from the leukocytes of the volunteers. 8-Oxoguanine glycosylase, which is also known as OGG1 is a DNA glycosylase enzyme that, in humans, is encoded by the OGG1 gene. This glycosylase removes 8oxoguanine (8-oxoG) DNA lesions and play an important in Base Excision Repair (BER) pathway. This pilot study reveals that the expression of OGG1 has been increased due to chronic arsenic exposure. This clearly indicates that excess generation of ROS due to chronic arsenic exposure has led to increased 8-oxoG accumulation, which in turn results into increased expression of OGG1 to counter its effect (Roy et al., 2011). Expression of other enzymes belonging to the BER and other pathways has also been investigated. X-ray repair crosscomplementing protein1 (XRCCI), DNA ligase I and DNA ligase III which also play very important role in BER (Hanssen-Bauer et al., 2012) has been found to decrease in the arsenic exposed volunteers. XRCCI identifies the apurinic/apyrimidinic (AP) sites within the damaged cell and recruits other DNA repair enzymes, while DNA ligases play an important role in ligating the excised DNA, thus repairing it. The decreased expression of these enzymes clearly indicates compromised DNA repair machinery within the arsenic exposed individuals. DNA polymerase $\beta$, which is also involved in recognizing the damaged DNA segment play an important role in BER. However, in this study there is no change in the expression of DNA polymerase $\beta$ with the samples hailing from arsenic endemic region. PARP1 plays important role in many DNA repair pathways like BER, NER as well as Non Homologous End Joining (NHEJ) pathway. Results reveal downregulation of PARP in affected samples. The results may be explained in the line of previous findings from our laboratory 
(Mukherjee et al., 2007). PARP 1 has been found to antagonize DNA polymerase $\beta$ by competing with it to bind to the nicked DNA substrate formed during gap filling phase of BER (Sukhanova et al., 2010). The obtained results indicate the fact that people residing in arsenic endemic area have compromised DNA repair capacity in comparison to people residing in other areas due to their chronic arsenic exposure.

Arsenic is also known to induce inflammation and chronic inflammation aids in sustaining tumor microenvironment, hence promoting carcinogenesis (Multhoff et al., 2012). The status of pro-inflammatory cytokines IL-2 and IL-6 was investigated and we found that arsenic exposed volunteers had higher expression of these two cytokines indicating sustenance of prolonged inflammation in the exposed individuals. Another important transcription factor that abridges inflammation and carcinogenesis is NF- $\kappa \beta$. The present study also investigated the expression of p50 and p65 sub units of NF- $\kappa \beta$ and found a much higher expression of these proteins. The expression of p65 was even higher than that of $\mathrm{p} 50$ subunit. NF- $\kappa \beta$ plays an important role in promoting inflammation as well as secretion of pro-inflammatory cytokines. The dimerization of p50 and p65 subunits and their translocation into the nucleus leads to the activation of many cell survival and pro-inflammatory pathways (Martins et al., 2016). Thus, maintenance of chronic inflammation in arsenic exposed individuals increases their cancer risk.

Table.1 Telomerase activity in control and iAs exposed individuals

\begin{tabular}{|c|c|c|}
\hline \multirow{2}{*}{$\begin{array}{l}\text { Sample } \\
\text { Number }\end{array}$} & \multicolumn{2}{|c|}{ Telomerase Activity } \\
\hline $\mathbf{1}$ & Control & iAs exposed \\
\hline $\mathbf{2}$ & 65 & 157 \\
\hline $\mathbf{3}$ & 73 & 138 \\
\hline $\mathbf{4}$ & 59 & 113 \\
\hline $\mathbf{5}$ & 60 & 87 \\
\hline $\mathbf{6}$ & 43 & 118 \\
\hline $\mathbf{7}$ & 56 & 145 \\
\hline $\mathbf{8}$ & 38 & 59 \\
\hline $\mathbf{9}$ & 55 & 127 \\
\hline $\mathbf{1 0}$ & 68 & 90 \\
\hline $\mathbf{1 1}$ & 47 & 147 \\
\hline $\mathbf{1 2}$ & 52 & 116 \\
\hline $\mathbf{1 3}$ & 64 & 89.5 \\
\hline $\mathbf{1 4}$ & 39 & 129 \\
\hline $\mathbf{1 5}$ & 54 & 148 \\
\hline
\end{tabular}

The values represent the band intensities of amplified product of telomeric repeats using the software Image Master 
Table.2 ROS as a modifier of several parameters

\begin{tabular}{|l|c|c|}
\hline \multicolumn{2}{|c|}{ Correlation between } & Correlation coefficient (R) \\
\hline ROS & TL & +0.72 \\
\hline ROS & OTM & +0.91 \\
\hline ROS & XRCC I & -0.95 \\
\hline ROS & DNA Ligase I & -0.87 \\
\hline ROS & DNA Ligase III & -0.98 \\
\hline ROS & PARP 1 & -0.96 \\
\hline ROS & OGG1 & +0.51 \\
\hline ROS & IL2 & +0.894 \\
\hline ROS & IL6 & +0.846 \\
\hline ROS & NFkB p50 & +0.930 \\
\hline ROS & NFאB p65 & +0.974 \\
\hline ROS & Telomerase & +0.92 \\
\hline
\end{tabular}

*The negative sign signifies that with increase in ROS level, there has been a decrease in the expression level of repair enzymes. **The positive sign shows that increase in ROS leads to increase in comet tail length, Olive tail moment, expression of pro-inflammatory cytokines, NFkB, as well as telomerase activity.

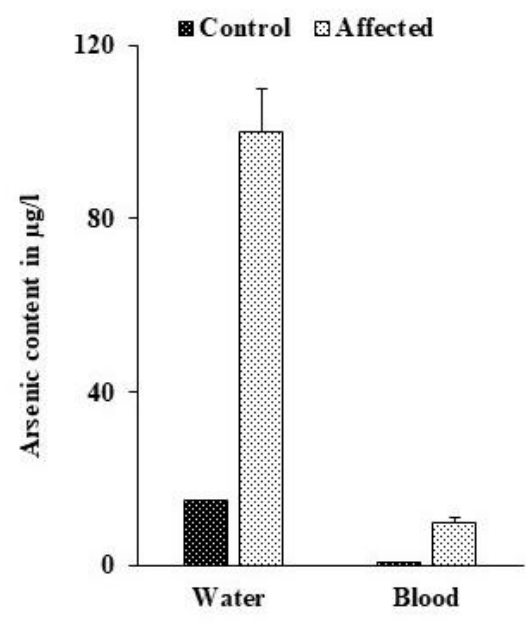

(A)

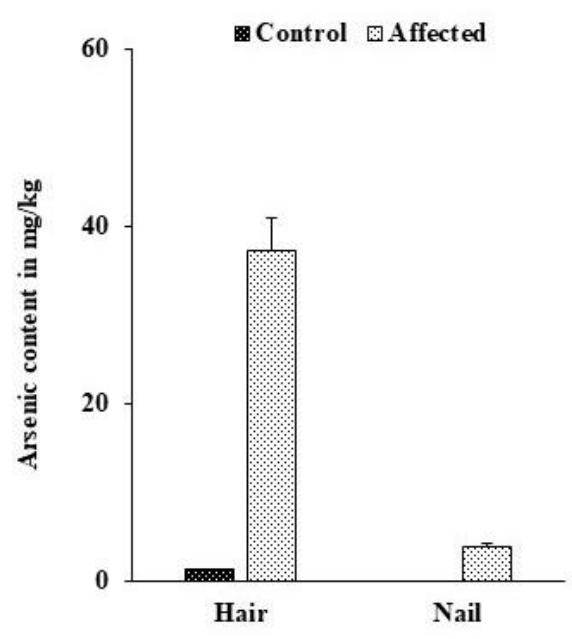

(B)

Figure.1 The bar graph represents the mean value of the arsenic content in the water, blood, hair and nails of the individuals from control areas, as well as iAs endemic area. Fig 1A shows the iAs level in the water they consume and the level of the same in their blood. The experiments have been repeated thrice and iAs for water is the average of three experiments \pm SD. The iAs content in blood is the average of 15 volunteers \pm SD. Fig 1B represents the iAs content in the hair and nail samples collected from the volunteers. The values show the average of 15 individuals along with SD. 

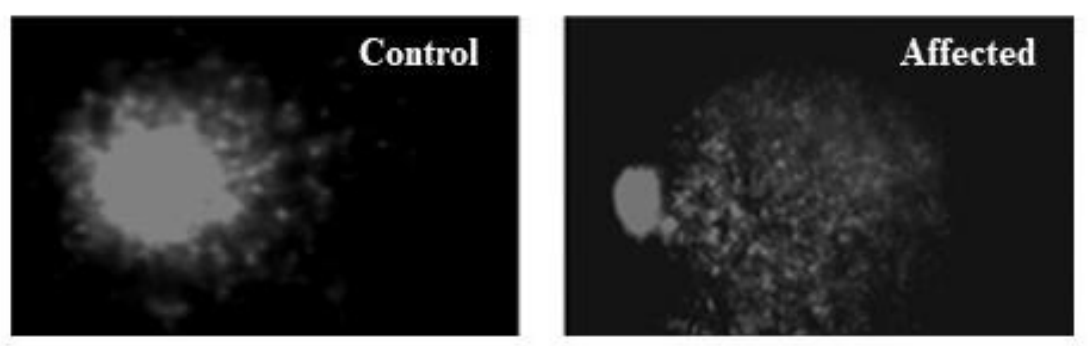

(A)

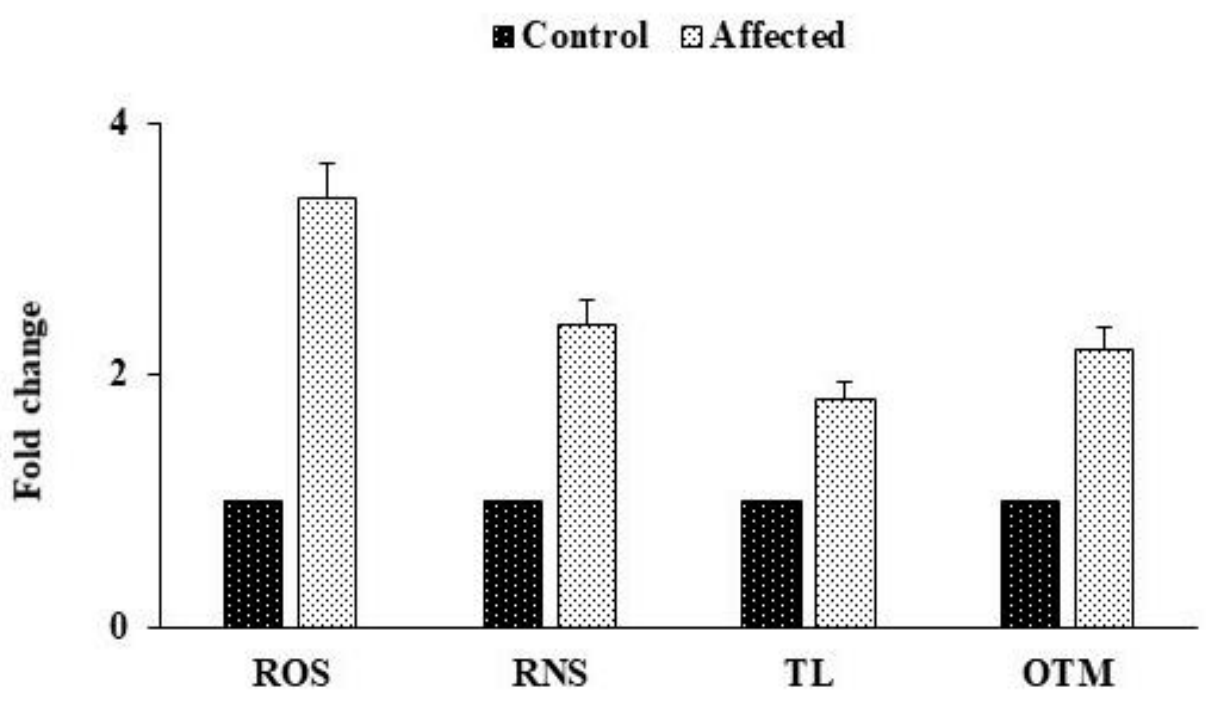

(B)

Figure.2 Comet pattern as obtained from Single Cell Gel Electrophoresis show the extent of DNA damage in leukocytes. Representative photographs reveal that in control, there is no damage, whereas in arsenic endemic area, tail length is high, indicating DNA damage due to arsenic exposure (Fig 2A). Fig 2B shows the extent of ROS and RNS in control and arsenic exposed samples. The extent of DNA damage is not exactly the same for all exposed individuals and the average of 15 volunteers from control and affected areas have been given \pm SD. Tail length is measured using a comet assay software. Tail moment (TM) incorporates a measure of both the smallest detectable size of migrating DNA (reflected in the comet tail length) and the number of relaxed / broken pieces (represented by the intensity of DNA in the tail). Olive Tail Moment (OTM) is another means of expressing DNA damage. 


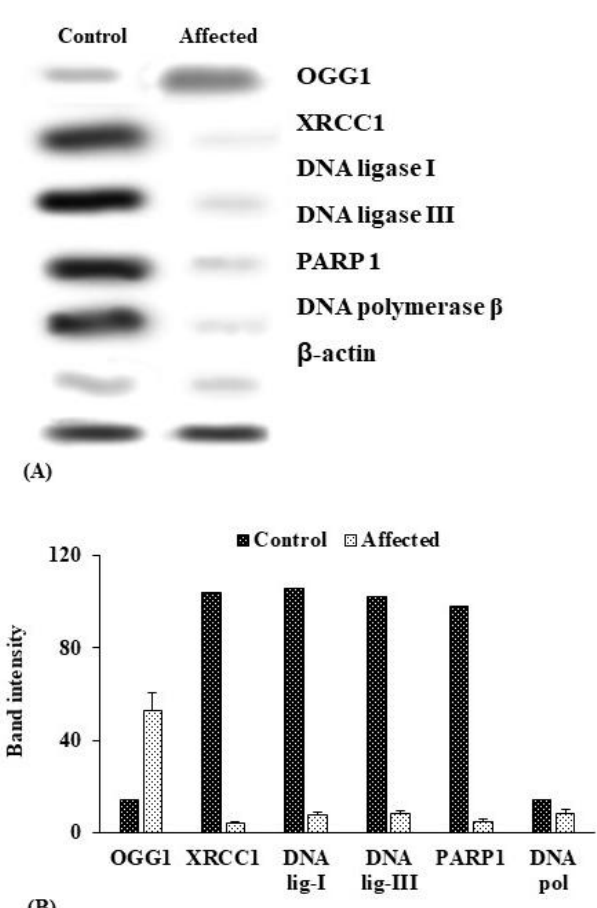

(B)

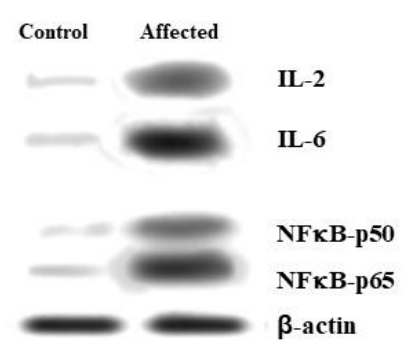

(C)

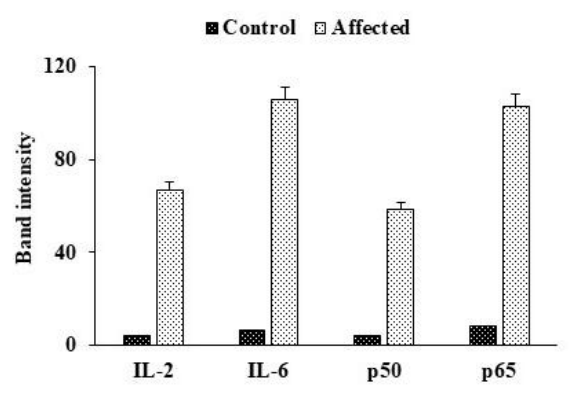

(D)

Figure.3 The figure represents the western blot analysis of repair enzymes, as well pro-inflammatory cytokines and transcription factor NFKB. Fig 3A shows the representative western blot results of DNA repair enzymes OGG1, XRCC1, DNA Ligase I, DNA Ligase III, PARP 1 and DNA Polymerase $\beta$ in control and arsenic affected population. The average band intensities of 15 volunteers from control and the same number from affected population are shown in Fig 3B. Fig 3C depicts the representative western blot bands of pro-inflammatory cytokines IL-2, IL-6 and transcription factor NFKB (p50 and p65 sub units) in control and iAs exposed volunteers. Fig 3D shows the average band intensities of IL2, IL6 and $\mathrm{NF} \kappa \mathrm{B}$ in control and exposed samples. Downregulation of repair enzymes, and upregulation of IL2, IL6 and $\mathrm{NF} \kappa \mathrm{B}$ is apparent from the results.

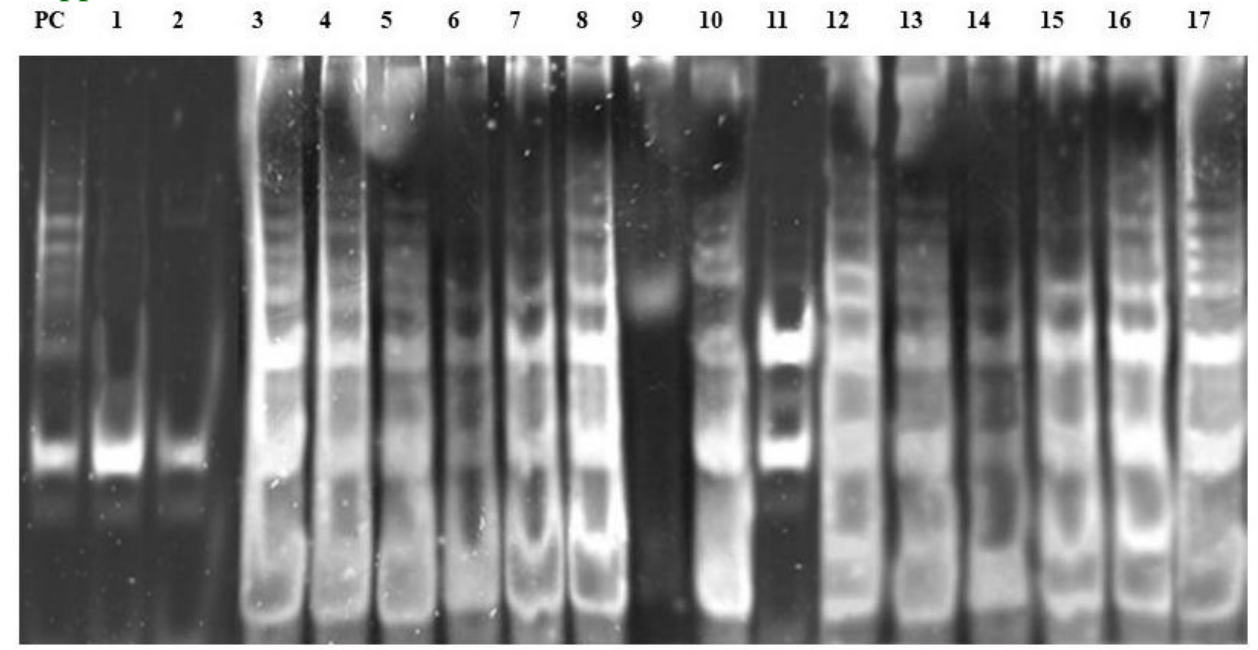

Figure.4 Telomerase activity as assessed by the TRAP assay method. The lane PC represents the positive control. Lanes 1 and 2 are the telomeric repeat ladder of the individuals from the nonarsenic zone while lanes $3-17$ are the telomeric repeat ladder of the individuals from the arsenic exposed region. The intensity of the lanes 3 - 17 are much higher, indicating higher telomerase activity in the individuals from the arsenic exposed region. Only exception is Lane 9. 
The length of the chromosomes determines the replicative capacity of the cell (Allsopp et al., 1992). Cells with damaged or shortened chromosomes cannot undergo cell division leading to check in the cell cycle and ultimately death of the cell through senescence. The telomeres along with the shelterin complexes play an important role in maintaining the shape of the chromosome (Diotti \& Loayza, 2011). Telomerase, a ribonucleoprotein, helps in the synthesis of innumerable telomeric repeats which cap the chromosome ends. In normal cells the activity of Telomerase is quite limited and after undergoing requisite number of replications, the telomeres get eroded away due to low telomerase activity. In subsequent replications, the chromosome ends get eroded thus halting cell division, but, in cancer cells, the telomerase activity is quite high which promote them to divide indefinitely (Jafri et al., 2016).

Therefore, activity of telomerase can be considered as a biomarker of cancer progression. In this pilot study we investigated the activity of telomerase in the volunteers from the arsenic contaminated and arsenic free regions. The results show that arsenic exposed individuals had much higher activity of telomerase than the non-exposed individuals, indicating that the arsenic exposed population was at a much higher risk of cancer than the unexposed individuals.

The correlation obtained showed that high generation of ROS due to iAs inhibits the repair enzymes, hence shattering the repair machinery. One exception is OGG1. Besides, Comet assay results show that DNA damage is increased appreciably. As repair system is compromised due to chronic exposure to iAs, the DNA damage retains, finally leading to carcinogenesis. Besides, pro-inflammatory cytokines and $\mathrm{NF \kappa B}$ increases, further contributing to carcinogenesis. Positive correlation between ROS generation and telomerase activity also support the notion.

The data obtained from this pilot study clearly indicates that people residing in areas with high level of inorganic arsenic in groundwater accumulate the metalloid in their hair and nails. This chronic exposure to arsenic leads to increased ROS and RNS generation and as a consequence results in DNA damage. Inhibition of DNA repair pathways and prolonged inflammation are also an outcome of chronic exposure to arsenic. Impaired DNA repair machinery and inflammation give a hint that these individuals are at higher risk of developing cancer. The telomerase assay results also support this finding. This study reveals that individuals exposed to arsenic have higher telomerase activity and are thus more susceptible to develop cancer. This pilot study was carried out with 15 control and 15 arsenic affected samples only, therefore, more studies need to be carried out at a much larger scale with much larger sample size to come to definite conclusion. With much large sample size, the telomerase activity assay can also be correlated with the expression of other cancer markers.

\section{Acknowledgement}

The authors are indebted to Dept of Biotechnology (DBT), Government of India, New Delhi, India for financial support and Director, Chittaranjan National Cancer Institute, Kolkata, India for providing infrastructural facilities.

\section{References}

Allsopp, R. C., Vaziri, H., Patterson, C., Goldstein, S., Younglai, E. V., Futcher, A. B., Greider, C. W., \& Harley, C. B. 1992. Telomere length predicts replicative capacity of human fibroblasts. P.N.A.S. 89(21), 10114-10118.

Andrew A.S., Karagas M.R., \& Hamilton J.W. 
2003. Decreased DNA repair gene expression among individuals exposed to arsenic in united states drinking water. Int. J. Cancer.104, 263-268.

Balasubramanyam, M., Koteswari, A.A., Kumar, R.S., Monickaraj, S.F., Maheswari, J.U., Mohan, V. 2003. Curcumin induced inhibition of reactive oxygen species generation: novel therapeutic implications. J. Biosci. 28,715-721.

Cadet, J., \& Wagner, J. R. (2013). DNA base damage by reactive oxygen species, oxidizing agents, and UV radiation. Cold Spring Harb. Perspect. Biol. 5(2), 1-18.

Dangleben, N.L., Skibola, C.F. \& Smith, M.T. 2013. Arsenic immunotoxicity: a review. Environ. Health. 12, 1-15.

Diotti, R., \& Loayza, D. 2011. Shelterin complex and associated factors at human telomeres. Nucleus (Austin, Tex.). 2(2), 119-135.

Ebert, F., Weiss, A., Bultemeyer, M., Hamann, I., Hartwig, A. \& Schwerdtle, T. 2011. Arsenicals affect base excision repair by several mechanisms. Mutat. Res. 715, 3241.

Ferrario, D., Collotta, A., Carfi, M., Bowe, G., Vahter, M., Hartung, T., \& Gribaldo, L. 2009. Arsenic induces telomerase expression and maintains telomere length in human cord blood cells. Toxicol.260(13), 132-141.

Green, L.C., Wagner, D.A., Glogowski, K., Skipper, P.L., Wishnok , J.S., Tannenbaum, S.R. 1982. Analysis of nitrate, nitrite and $[15 \mathrm{~N}]$ nitrate in biological fluids. Anal. Biochem. 126, 131-138.

Hanssen-Bauer, A., Solvang-Garten, K., Akbari, M., \& Otterlei, M. 2012. X-ray repair cross complementing protein 1 in base excision repair. Int. J. Mol. 13(12), 17210-17229.

Huang, H. W., Lee, C. H., \& Yu, H. S. 2019. Arsenic-Induced Carcinogenesis and Immune Dysregulation. Int. J. Environ. Res. Public Health. 16(15), 2746, 2-7.

Jafri, M. A., Ansari, S. A., Alqahtani, M. H., \&
Shay, J. W. 2016. Roles of telomeres and telomerase in cancer, and advances in telomerase-targeted therapies. Genome Med. 8(1), 69, 1-19.

Jomova, K., Jenisova, Z., Feszterova, M., Baros, S., Liska, J., Hudecova, D., Rhodes, C.J., \& Valko, M. 2011. Arsenic: toxicity, oxidative stress and human disease. J. Appl. Toxicol. 31(2), 95-107.

Karagas, M.R., Tosteson, T.D., Morris, J.S. Demidenko, E., Mott, L.A., Heaney, J., \& Schned, A. 2004. Incidence of Transitional Cell Carcinoma of the Bladder and Arsenic Exposure in New Hampshire. Cancer Causes Control. 15, 465-472.

Khairul, I., Wang, Q.Q., Jiang, Y.H., Wang, C., \& Naranmandura, H. 2017. Metabolism, toxicity and anticancer activities of arsenic compounds. Oncotarget. 8(14), 2390523926.

Kim, N.W., Piatyszek, M.A., Prowse, K.R., Harley, C.B., West, M.D., Ho, P.L., Coviello, G.M., Wright, W.E., Weinrich, S.L., \& Shay, J.W. 1994. Specific association of human telomerase activity with immortal cells and cancer. Sci. 266(5193), 2011-2015.

Ko, E., Seo, H.W., \& Jung, G. 2018. Telomere Length and Reactive Oxygen Species Levels Are Positively Associated With a High Risk of Mortality and Recurrence in Hepatocellular Carcinoma J. Hepatol. 67(40), 1378-1391.

Kumaravel, T.S., Vilhar, B., Faux, S.P., \& Jha, A.N. 2009. Comet Assay measurements: a perspective. Cell. Biol. Toxicol. 25, 5364.

Martinez, V.D., Vucic, E.A., Becker-Santos, D.D., Gil, L., \& Lam, W.L.2011. Arsenic Exposure and the Induction of Human Cancers. J.Toxicol. 2011, 431287, 1-14.

Martins, G.R., Gelaleti, G.B., Moschetta, M.G., Maschio-Signorini, L.B., \& Zuccari, D.A.P.D.C. 2016. Proinflammatory and Anti-Inflammatory Cytokines Mediated by $\mathrm{NF}-\kappa \mathrm{B}$ Factor as Prognostic Markers in Mammary Tumors. Mediat. Inflamm. 2016, 9512743, 1-10.

Mazumder, D.G., \& Dasgupta, U.B. 2011. 
Chronic arsenic toxicity: Studies in West Bengal, India. Kaohsiung J. Med. Sci. 27, 360-370.

Mukherjee, S., Roy, M., Dey, S. and Bhattacharya, R. K. 2007. A Mechanistic Approach for Modulation of Arsenic Toxicity in Human Lymphocytes by Curcumin, an Active Constituent of Medicinal Herb Curcuma longa Linn. Journal of Clinical Biochemistry and Nutrition. 41, 32-42.

Multhoff, G., Molls, M., \& Radons, J. 2012. Chronic inflammation in cancer development. Front. Immunol. 2(98), 117.

Roy, M., Kunnumakkara, A.B., Mukherjee, A., Sarkar, R., Mukherjee, S., \& Biswas. J. 2015. Repair Activity Impaired by Arsenic: Recovery by Phytochemicals. Int.J.Curr.Microbiol.App.Sci. 4(3), 578587.

Roy, M., Mukherjee, A., Mukherjee, S., \& Biswas, J. 2014. Arsenic: an alarming global concern. Int.J.Curr.Microbiol.App.Sci. 3(10), 3447.

Roy, M., Sinha, D., Mukherjee, S. \& Biswas, J. 2011. Curcumin prevents DNA damage and enhances the repair potential in a chronically arsenic-exposed human population in West Bengal, India. Eur $\mathbf{J}$ Cancer Prev. 20(2), 123-131.

Sarkar, R., Mukherjee, A., Biswas, R., Biswas, J., \& Roy, M. 2014. Sulphoraphane, by virtue of its antioxidant potential downregulates HSP90 in leukemia cells. Int.J.Curr.Microbiol.App.Sci. 3(1), 476-
486.

Schoen, A., Beck, B., Sharma, R., \& Dubé, E. 2004. Arsenic toxicity at low doses: epidemiological and mode of action considerations. Toxicol. Appl. Pharmacol. 198(3), 253-267.

Smith, A. H., Ercumen, A., Yuan, Y., \& Steinmaus, C. M. 2009. Increased lung cancer risks are similar whether arsenic is ingested or inhaled. J. Expo. Sci. Environ. Epidemiol. 19(4), 343-348.

Smith, K.R., Klei, L.R. \& Barchowsky, A. 2001. Arsenite stimulates plasma membrane NADPH oxidase in vascular endothelial cells. Am. J. Physical. Lung Cell. Mol. Physiol. 280, 442-449.

Telomeres Mendelian Randomization Collaboration, Haycock, P. C., Burgess, S., Nounu, A., Zheng, J., Okoli, G. N., Bowden, J., Wade, K. H., Timpson, N. J., Evans, D. M., Willeit, P., Aviv, A., Gaunt, T. R., Hemani, G., Mangino, M., Ellis, H. P., Kurian, K. M., Pooley, K. A., Eeles, R. A., Lee, J. E., ... Davey Smith, G. 2017. Association Between Telomere Length and Risk of Cancer and Non-Neoplastic Diseases: A Mendelian Randomization Study. JAMA oncology, 3(5), 636-651.

Zhang, Z., Pratheeshkumar, P., Budhraja, A., Son, Y. O., Kim, D., \& Shi, X. 2015. Role of reactive oxygen species in arsenicinduced transformation of human lung bronchial epithelial (BEAS-2B) cells. Biochem. Biophys. Res. Commun. 456(2), 643-648.

\section{How to cite this article:}

Archismaan Ghosh, Apurba Mukherjee, Sutapa Mukherjee and Madhumita Roy. 2020. Assessment of Susceptibility towards iAs Induced Carcinogenesis in West Bengal, India. Int.J.Curr.Microbiol.App.Sci. 9(03): 1998-2011. doi: https://doi.org/10.20546/ijcmas.2020.903.232 